\title{
"Ganhar as coisas na maciota": argumentação e retórica nas conversações online sobre as cotas raciais nas universidades
}

\section{Cunning tactics: argumentation and rhetoric in online conversations about racial quotas in universities}

Luciane Leopoldo Belin'1, Carla Candida Rizzotto², Camilla Hoshino³, Djiovanni Jonas França Marioto ${ }^{4}$ e Vitor Lieb/5 do Paraná (UFPR), pesquisadora do grupo de pesquisa Comunicação e Participação Política (Compa), bolsista Capes. E-mail: Iucianebelin@gmail.com. de pesquisa Compa, bolsista Capes. E-mail: djiovannimarioto@gmail.com. 


\section{Resumo}

Este artigo apresenta uma reflexão sobre a discussão acerca da política de cotas raciais no Brasil. Com o objetivo de verificar de que forma os argumentos em torno da ação afirmativa se relacionam com as estratégias retóricas mobilizadas para sua expressão, a pesquisa é orientada pelo seguinte questionamento: sob quais condições comunicativas as opiniões dos indivíduos contrários e favoráveis às cotas raciais nas universidades se formam e se expressam nas conversações online? O corpus é composto por 4.333 comentários postados nas redes sociais YouTube, Facebook e Twitter, analisados com base em um livro de códigos, cujas variáveis (tema da conversação, posicionamento do comentário, argumentos e estratégias retóricas) são traçadas a partir da perspectiva da retórica e da deliberação.

\section{Palavras-chave}

Cotas raciais, conversações online, retórica.

\section{Abstract}

This article presents a reflection on the discussion about the racial quota policy in Brazil. To verify how the arguments around the affirmative action relate to the rhetorical strategies mobilized for their expression, the research follows the question: under which communicative conditions are the opinions of individuals contrary and favorable to racial quotas in universities formed and expressed in online conversations? The research corpus consists of 4,333 comments posted on the social medias YouTube, Facebook, and Twitter, based on a code book, whose variables (topic of conversation, commentary position, arguments, and rhetorical strategies) are drawn from the perspective of rhetoric and deliberation.

\section{Keywords}

Racial quotas, online conversations, rhetoric. 
O debate sobre ações afirmativas iniciou-se na década de 1960, nos Estados Unidos, principalmente a partir do movimento dos negros em prol da igualdade de oportunidades, fomentado por grupos como o partido dos Panteras Negras. Em 1976, a União Europeia adotava suas primeiras ações, que contemplavam o mercado de trabalho, o campo educacional e a representação política, em caráter voluntário e não obrigatório (MOEHLECKE, 2002, p. 199).

Diferentemente desse modelo, que era comumente chamado de "discriminação positiva", a ação afirmativa assumiu outras formas, sendo a mais conhecida a reserva de uma quantidade de vagas em concursos e vestibulares para estudantes de grupos específicos (MOEHLECKE, 2002, p. 199) - no Brasil, negros, indígenas e estudantes de escolas públicas.

Segundo Barbosa Gomes, ações afirmativas têm como objetivo "induzir transformações de ordem cultural, pedagógica e psicológica, visando tirar do imaginário coletivo a ideia de supremacia racial" (GOMES, 2001, p. 6-7). Estas políticas têm, ainda conforme o autor, as finalidades de "coibir a discriminação do presente e eliminar os efeitos persistentes da discriminação do passado; implantar a diversidade e ampliar a representatividade dos grupos minoritários nos diversos setores" (GOMES, 2001, p. 6-7).

No Brasil, o Projeto de Lei no 1.332 , de 14 de junho de 1983, foi o primeiro a traduzir para a esfera constitucional o pensamento acerca das ações afirmativas. Proposto pelo então deputado federal Abdias do Nascimento (PDT/RJ), visava à "isonomia do negro" na sociedade brasileira a partir da reserva de $20 \%$ de vagas universitárias para mulheres negras e $20 \%$ para homens negros, entre outras propostas. Embora arquivado, o projeto encorajou o debate sobre o tema. A primeira política brasileira de cotas ocorreu em 1995, a partir de uma legislação eleitoral, estabelecendo a cota mínima de 30\% de mulheres nas candidaturas eleitorais. Dentro do movimento negro, os pedidos por mudança e igualdade só aumentavam, culminando em grandes movimentações como a marcha Zumbi de 1996 (MOEHLECKE, 2002, p. 205).

No entanto, as leis que visam à expansão e consolidação das igualdades sociais para a população negra só foram possíveis após a "III Reunião mundial contra 
o racismo, discriminação racial, xenofobia e intolerância correlata, em Durban, no ano de 2001. Nela, o Brasil reconheceu que precisava adotar medidas de reparação a vítimas de racismo por meio de políticas públicas, principalmente nos âmbitos da educação e do trabalho" (MUNANGA, 2001, p. 35).

Com o passar dos anos, a temática das ações afirmativas tornou-se mais presente nos jornais: entre os anos de 2001 e 2009, nos jornais Folha de S.Paulo, O Globo e Estado de Minas, o debate sobre cotas raciais teve um caráter polarizado em colunas assinadas e editoriais, além de uma ampla participação do "cidadão comum" (em contraste com o governo federal e especialistas), principalmente no espaço dedicado a cartas de leitores (BOTELHO; MAIA; MUNDIM, 2011, p. 10).

Baseando-se nesse histórico e no protagonismo da argumentação polarizada no debate sobre cotas como ações afirmativas, este artigo tem como objetivo verificar de que forma os argumentos a respeito das políticas de cotas nas universidades se relacionam com as estratégias retóricas mobilizadas para sua expressão. O problema desta pesquisa se formula da seguinte maneira: sob quais condições comunicativas as opiniões dos indivíduos contrários e favoráveis às cotas nas universidades se formam e se expressam nas conversações online?

Para respondê-lo, o artigo baseia-se no arcabouço teórico da retórica e da deliberação, apresentados no primeiro tópico, e analisa 4.333 comentários feitos em postagens relacionadas ao tema no Facebook, no YouTube e no Twitter. O corpus e a metodologia empregados são detalhados no tópico seguinte e, no terceiro item, estão os principais resultados encontrados, que sugerem que, nas três plataformas analisadas, a retórica propositiva e com apelo pragmático é a predominante, e que há racionalidade, ou seja, justificação dos posicionamentos, tanto entre os contrários quanto entre os favoráveis às cotas, embora os contrários sejam os mais predispostos a elucidar um posicionamento seguido da apresentação de seus motivos. Percebe-se, ainda, que os principais argumentos mobilizados para sustentar uma posição favorável às cotas são aqueles que desafiam a credibilidade da fonte de que se extrai a crença dos opositores. 


\section{Retórica, deliberação e conversações cotidianas}

Garsten (2011) aponta que a retórica parece ter encontrado um novo fôlego na teoria política nas últimas décadas, com um aumento significativo e relativamente recente no interesse por esse campo. O autor vê esse renovado interesse, em parte, como um reflexo do descontentamento dos teóricos com a normatividade rígida dos estudos sobre democracia deliberativa, em especial pela imposição inerente dessa teoria (na perspectiva habermasiana) sobre que tipos de argumentos são válidos para legitimar uma deliberação.

Habermas $(1984,1997)$ define a democracia deliberativa como um modelo que enfatiza a necessidade de participação da esfera civil nas decisões políticas por meio do debate público pautado na racionalidade. Garsten, por sua vez, sugere que a deliberação habermasiana exclui outros tipos de discurso com base no suposto pretexto de que debates descentrados na racionalidade ferem a autonomia dos participantes. Para o autor, "a deliberação habermasiana tem como elemento central a visão kantiana de que a razão é a única forma de influenciar pessoas e ao mesmo tempo respeitar a autonomia delas" (GARSTEN, 2011, p. 167).

Levando em consideração a concepção presente em Górgias, de Platão, segundo a qual a retórica é o oposto do conhecimento e da verdade, é natural chegar à conclusão de que a democracia deliberativa, ao enfatizar o debate público pautado na racionalidade, não permite espaço para a retórica. No entanto, há autores que vêm tentando redefinir a retórica e inseri-la de maneira relevante nos estudos deliberativos. Entre eles, Chambers (2009) aponta que as críticas de Platão à retórica perpassam as críticas do filósofo à democracia. Na democracia, um regime de muitos, o poder é daquele capaz de persuadir o maior número de pessoas, sendo a retórica uma ferramenta ideal para atingir esse objetivo, por não ter comprometimento com a verdade, apenas com o convencimento e a persuasão. No entanto, a autora argumenta que esses ataques de Platão dizem respeito a um tipo de retórica, ao qual Chambers dá o nome de retórica plebiscitária.

Em oposição a esta, ela advoga pela versão deliberativa da retórica, que trataria representantes do público como debatedores autônomos e merecedores 
de respeito (CHAMBERS, 2009, p. 337). Na argumentação da autora, a ideia de autonomia dos deliberadores (presente em Habermas) é essencial. A retórica plebiscitária, ao podar essa autonomia, faz que a tomada de decisões seja uma questão de dominação. Nesse caso, o perigo é a possibilidade de as elites terem uma vantagem sobre os demais cidadãos, uma vez que têm mais acesso a ferramentas de comunicação política.

Outra autora importante para nossa análise da interface entre retórica e deliberação é Iris Young (2002). Apesar de definir suas ideias como parte do campo da teoria da democracia comunicacional, não da democracia deliberativa, a autora vê a retórica como benéfica para o debate democrático por apontar críticas válidas para expandir o conceito de deliberação na teoria de Habermas. Ao mudar o foco da deliberação para a comunicação, Young (2002) argumenta que outros tipos de discursos, não necessariamente centrados na definição habermasiana de racionalidade, são utilizados por grupos marginalizados para adentrar o debate público.

Para a autora, a retórica está ligada à forma da argumentação, que pode refletir diferenças culturais ou de outro tipo, englobando inclusive aspectos pragmáticos como saudações ou narrativas. Acima de tudo, Young (2002) vê a retórica como importante para a democracia porque representa a inclusão de variados discursos, uma vez que o discurso unicamente pautado pela racionalidade "diminui o papel da emoção, da linguagem figurativa e de formas de expressão lúdicas ou incomuns" (p. 63).

A partir dessas críticas, Young expande sua argumentação, comentando que grupos normalmente caracterizados como não tendo um discurso suficientemente neutro ou formal costumam ser aqueles menos poderosos e mais marginalizados da sociedade, concluindo que essa suposta "neutralidade" discursiva esconde a exclusão de outras formas de expressão. Em contrapartida, uma perspectiva deliberativa que aceite a retórica enquanto forma válida de discurso seria inerentemente uma teoria mais inclusiva. Essa inclusão só seria limitada pela exclusão de expressões desrespeitosas ou incoerentes. 
É importante aqui também ressaltar que essa perspectiva de Young não advoga por uma contraposição entre racionalidade (entendida no sentido habermasiano de argumentos "justificados") e emoções: o objetivo não é tornar a racionalidade menos relevante para a deliberação, mas sim defender o uso de recursos discursivos pautados na emoção como válidos para o processo deliberativo, podendo inclusive ser (idealmente) usados em conjunto com a racionalidade.

Assim, vemos na teoria de Young uma reabilitação discursiva das emoções. Apesar de a autora restringir a retórica a aspectos estilísticos e formais da discursividade, os argumentos apresentados são sólidos o suficiente para serem utilizados como validação das emoções em um sentido mais amplo: o apelo às emoções passa a ser uma estratégia discursiva legítima e até mesmo louvável no contexto deliberativo como forma de equilibrar desigualdades na capacidade de expressão, resultantes de discrepâncias sociais mais amplas. Assim como as ações afirmativas são utilizadas para alcançar uma sociedade mais igualitária, a perspectiva de Young mostra que é necessária uma mudança na valorização dos elementos argumentativos para que a luta pela igualdade ocorra não somente por meio de ações, mas também discursivamente.

\section{Corpus e metodologia}

O corpus desta pesquisa é composto por comentários a respeito da política de cotas nas universidades postados em três redes sociais. No Twitter, foram coletadas 367 postagens, publicadas em 20 de novembro de 2018, Dia da Consciência Negra. No Facebook, integram o conjunto de análise as respostas ao post mais comentado de 2018 sobre o tema em cada uma das seguintes páginas: jornais (El País, Folha de S.Paulo, Estadão, O Globo) e mídia alternativa (Quebrando o Tabu e Catraca Livre), totalizando 8.719. Por fim, no YouTube foram incluídos os comentários de três vídeos sobre o assunto, sendo um de mídia tradicional (portanto neutro, a princípio), e dois com posições opostas, num total de 3.255.

A partir deste universo inicial, foi realizado um cálculo amostral com erro de $2 \%$ e nível de confiança de $99 \%$. Da amostra resultante, foram excluídos 
os que continham somente marcação de outros indivíduos ou emojis, gerando um corpus de análise final de 4.333 comentários.

A análise teve como base um livro de códigos desenvolvido por Rizzotto (2018) em uma pesquisa-macro que visa compreender a que estratégias comunicacionais recorrem os indivíduos na formulação e na exposição de suas opiniões sobre temas polêmicos, com vistas ao convencimento de seus interlocutores. Como temas polêmicos optou-se pelas discussões em torno das cotas raciais nas universidades, da Lei do Feminicídio (RIZZOTTO; SARAIVA, 2020) e da descriminalização do aborto (RIZZOTTO; BELIN, 2019), que envolvem em sua discussão o resgate de histórias de vida e nas quais é perceptível uma profunda influência de valores individuais ${ }^{6}$.

No entanto, para este artigo, optamos por analisar unicamente as variáveis que nos permitem realizar inferências acerca da utilização da retórica enquanto forma legítima de convencimento, embora estejam também associadas às demais variáveis, uma vez que o livro de códigos foi elaborado com base na teoria deliberacionista, que observa os aspectos das discussões como imbricados.

\section{Análise e resultados}

Após analisar os 4.333 comentários provenientes dos espaços já citados buscando responder à pergunta proposta - sob quais condições comunicativas as opiniões dos indivíduos contrários e favoráveis às cotas nas universidades se formam e se expressam nas conversações online? -, foi possível identificar alguns aspectos sobre a relação entre os argumentos dos indivíduos participantes ${ }^{7}$ e as estratégias retóricas empregadas. Serão descritos os resultados da análise de frequência simples das variáveis selecionadas e, em seguida, alguns cruzamentos que ajudam a discutir a questão proposta. 
A variável de posicionamento $\left(\mathrm{V} 21^{8}\right)$ permite comparar, mais adiante, as estratégias utilizadas pelos indivíduos que assumem posicionamentos divergentes. Como foram analisados aleatoriamente, em 2.743 dos comentários (63\% do corpus) não foi possível identificar o posicionamento do comentarista. Entre as 1.590 unidades de análise em que havia posicionamento claro, identificou-se que $55,2 \%$ são contrários às políticas de cotas e $44,7 \%$ são favoráveis, o que indica um debate relativamente equilibrado.

Tendo identificado os posicionamentos, foram mapeados os argumentos (V21.1) mais presentes para justificá-los. Dentre os contrários, aparecem: (a) igualdade: todos são iguais perante a lei e as cotas seriam uma forma de racismo (13\% dos comentários válidos); (b) não há dívida histórica: justifica-se que não há dívida histórica, o problema da escravidão já foi resolvido (5,2\%); (c) "racismo reverso": defende-se que as cotas são uma forma de racismo contra brancos $(1,1 \%)$; (d) cota social: argumenta-se que o problema reside na educação básica, portanto as cotas sociais são uma melhor forma de resolvê-lo (10\%); (e) meritocracia: as pessoas devem entrar na universidade por mérito próprio, não com ajuda $(8,1 \%)$. Em 9,6\% dos comentários com posicionamento contrário evidente, o comentarista apenas se diz contra as cotas, mas não evidencia o motivo.

Já os principais argumentos favoráveis são: (a) dívida histórica: as cotas são uma maneira de compensar a dívida histórica da escravidão $(6,1 \%)$; (b) questões social e racial são atreladas: defende as cotas raciais como sociais, argumentando que a maior parte da população pobre é, também, negra $(3,1 \%)$; (c) racismo estrutural da sociedade brasileira (7\%); (d) meritocracia é uma falácia $(6,5 \%)$. Por fim, $16 \%$ dos comentaristas favoráveis às cotas assumem esse posicionamento, mas não apresentam argumentos.

Em seguida estão as variáveis que nos fornecem indicativos acerca dos critérios deliberativos: o turno da fala (V4), o tema da conversação (V5), a forma do comentário (V6) e a racionalidade (V7). Quanto ao tema da conversação, 
a codificação se divide em: comentários fora do tema; estruturais, referindo-se de maneira direta às cotas raciais; relacionais, que tratam de temas adjacentes; ou ainda, desconhecido, caso não seja possível a identificação do assunto tratado. Excetuando os desconhecidos $(23,1 \%)$ que alcançam um alto índice, uma vez que não analisamos a sequência da comunicação (thread), mas somente os comentários isolados, temos que $64,5 \%$ permanecem no tema, enquanto $35,4 \%$ são off topic. Dos inseridos na temática, $56,4 \%$ são relacionais e $43,5 \%$ são estruturais.

O turno da fala (V4) mostra que $75 \%$ dos comentários são novos e somente $25 \%$ são de respostas a outros comentaristas, indicando a baixa presença de reciprocidade. Na variável de forma (V6), na mesma direção, temos que $72,6 \%$ dos comentários são simples declarações/afirmações, seguidos por $10,2 \%$ de comentários que buscam estabelecer conflito. As formas que indicam engajamento aparecem muito pouco: ponto de vista oposto $(7,4 \%)$, questionamento $(5,8 \%)$, proposição de solução $(1,9 \%)$, esclarecimento $(1,3 \%)$ e chamada para a ação $(0,5 \%)$.

A racionalidade (V7) está presente em 41,4\% dos comentários. Quando observados somente os comentários cujo posicionamento é identificável, esse índice sobe para 77,4\% dos comentários contrários e 79\% dos favoráveis. A presença significativa de justificação das opiniões mostra que se trata de uma discussão que frequentemente alcança níveis satisfatórios de aprofundamento, por exemplo:

Igualdade perante a lei é termos as mesmas oportunidades. Antes das leis de cotas, mais de $50 \%$ dos jovens negros estudantes de escola pública dividiam seu tempo de estudo com trabalho. Quer falar de igualdade com realidades tão distintas? Sério! Chega a ser falta de caráter questionar o mínimo que se faz para reduzir as diferenças. [...] Inegável a deficiência do Estado nesse contexto. Mas nesse caso, invés de focar em cotas, deveriam focar em melhorar a deficiente educação básica. Com uma educação de base boa, seus alunos não necessitariam de cotas para ter acesso ao ensino superior, concorda?! [...] Concluo dizendo que a política de cotas é importante para amenizar as consequências do racismo, no entanto, creio que seja mais adequado solucionar a raiz do problema: educação básica, a qual levará alguns vários anos, devido a postura do governo brasileiro. 
Entretanto, é fundamental ressaltar que a presença da racionalidade não é diretamente oposta à presença de estratégias retóricas emocionais. Entendemos como racionais os comentários que de alguma forma justificavam sua opinião, mesmo que essa justificativa se fizesse presente na forma de contação de histórias pessoais:

A última vez que fiz a inscrição pro Prouni, coloquei que era parda, aí pode escolher (não usei cotas mas quis vê) se quer ou não usar o sistema de cotas, e além de ter menor número de bolsas a nota de corte estava maior, o que significa que tinham muito mais pessoas concorrendo aquelas vagas, ou seja, não entra qualquer um, é por mérito e não de mão beijadas.

Foram codificados também os recursos argumentativos (V10 até V14) usados pelos participantes do debate: o insulto aparece em 12,3\%, o sarcasmo em $8,8 \%$, a analogia em 5\%, a narração em 4,3\% e a ameaça aparece em apenas $1 \%$ dos casos.

Por fim, as estratégias persuasivas (V9), que se dividem em: (a) propositiva/apelo pragmático, que trata de efeitos e consequências práticas ou então tenta mostrar como as coisas são; (b) sedutora ou ameaçadora/apelo emocional, que busca convencer o interlocutor através da persuasão, utilizando para tanto argumentos emocionais e não racionais; (c) ético-moral/apelo ideológico, na qual o comentarista baseia seu posicionamento em "certo" ou "errado"; e (d) crítica/apelo à credibilidade da fonte, que tece uma crítica focada nos sujeitos aos quais se opõem.

A estratégia mais aparente é a propositiva $(30,5 \%)$, seguida por ético-moral (17\%), crítica $(15,4 \%)$ e sedutora (4,2\%). Esta ordem não se altera quando cruzamos as estratégias com o posicionamento do comentarista, porém há diferença no uso das retóricas ético-moral e crítica: os sujeitos contrários às cotas recorrem mais a argumentos retoricamente pautados em questões de ordem moral, enquanto os favoráveis empregam mais frequentemente a retórica crítica.

Em relação aos argumentos levantados, é interessante observar que a listagem obtida para justificar o posicionamento contrário a cotas raciais se relaciona justamente com dois produtos intelectuais das elites brancas dominantes, 
quais sejam o ideal do "branqueamento" e o mito da "democracia racial" brasileira, que buscaram socializar a população (brancos e negros igualmente), evitando potenciais conflitos sociais (HASENBALG, 2005). Como aponta Hasenbalg (2005), enquanto o contínuo de cor implicou a fragmentação da identidade racial dos não-brancos e transformou o potencial da ação coletiva em expectativas individuais de mobilidade ascendente, a ideia de democracia racial disseminou no país dois princípios que estabeleceram caráter permanente: a ausência de preconceito e discriminação racial; e a existência de oportunidades econômicas e sociais iguais para brancos e negros. Não à toa, o argumento da igualdade ganha destaque na exposição dos dados coletados, com frequência relevante da retórica ético-moral.

Já o arsenal reunido para defender a política das cotas raciais é, sobretudo, uma síntese da narrativa traçada pela luta de movimentos e intelectuais negros em busca de direitos sociais e ocupação dos espaços de discussão política, debate sintetizado no pensamento de Nascimento (1976, 1978, 1991), mesmo deputado federal responsável pela elaboração do primeiro projeto de lei a respeito de ações afirmativas por meio de cotas raciais. Aqui, o que se pode ver é que os principais argumentos mobilizados para sustentar uma posição favorável às cotas também são aqueles que desafiam a credibilidade da fonte de que se extrai a crença dos opositores, isto é, o mito da democracia racial, ideologia amplamente impregnada socialmente (HASENBALG, 2005). Essa leitura pode ajudar a compreender a maior presença da retórica crítica entre os favoráveis às cotas raciais, dinâmica que favorece a qualificação da comunicação política.

Em seguida, serão apresentados os resultados dos cruzamentos entre algumas dessas variáveis, ajudando a compreender de forma mais aprofundada as relações entre retórica, argumentação e os demais aspectos observados.

\section{Frequência cruzada}

No que diz respeito às estratégias retóricas, algumas diferenças de comportamento se fazem notar ao observar as diferentes plataformas. Nas três analisadas, a retórica propositiva, com apelo pragmático, é predominante sobre as demais 
e a sedutora/ameaçadora é a que menos aparece. Entretanto, há uma leve diferença entre o Facebook e o YouTube quando se observa o uso de retórica ético-moral/apelo ideológico e a crítica/apelo à credibilidade da fonte. Embora não seja uma disparidade gritante, a estratégia persuasiva ético-moral é mais forte no Facebook (382 casos, ao lado de 322 críticos), enquanto a crítica é levemente mais presente no YouTube (318 casos, mais do que os 299 casos de retórica ético-moral). No Twitter, a diferença é mais evidente, de forma que a retórica ético-moral aparece duas vezes mais do que a crítica (56 contra 28 casos) (Gráfico $1^{9}$ ).

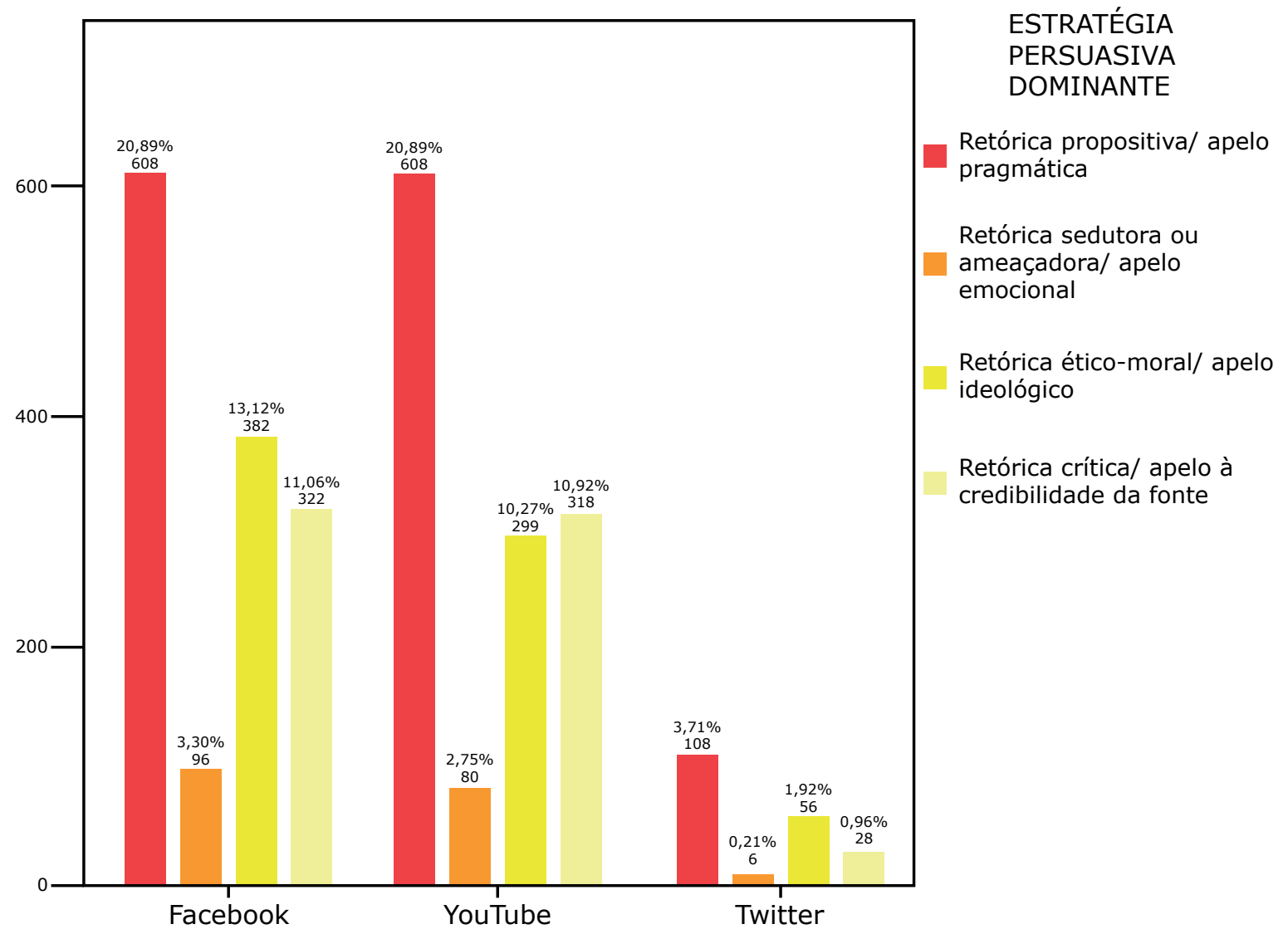

Gráfico 1: Estratégia persuasiva dominante (plataformas)

Fonte: Elaborado pelos autores. 
Quando observada em relação ao tema, a retórica propositiva ou pragmática mantém a predominância, seguida pela retórica ético-moral, tanto nos comentários estruturais quanto nos relacionais (Gráfico 2). Entretanto, esta última é mais frequente nos comentários relacionais em relação aos estruturais.

Uma explicação possível para essa diferença é que muitos dos comentários considerados relacionais são aqueles que justamente olham para assuntos relacionados com o tema proposto, mas sem discutir o assunto diretamente - ou seja, tratam de questões como a desigualdade social e educacional a partir de um olhar ideológico, mas não refletem sobre a questão das cotas. Por exemplo: "Falta cultura para esse Capitão do Mato. Ele pensa dessa forma pois também é vítima de todo esse sistema complexo de exclusão. É fruto de uma geração revoltada, mas sem capacidade intelectual para discernir sobre a essência real do preconceito".

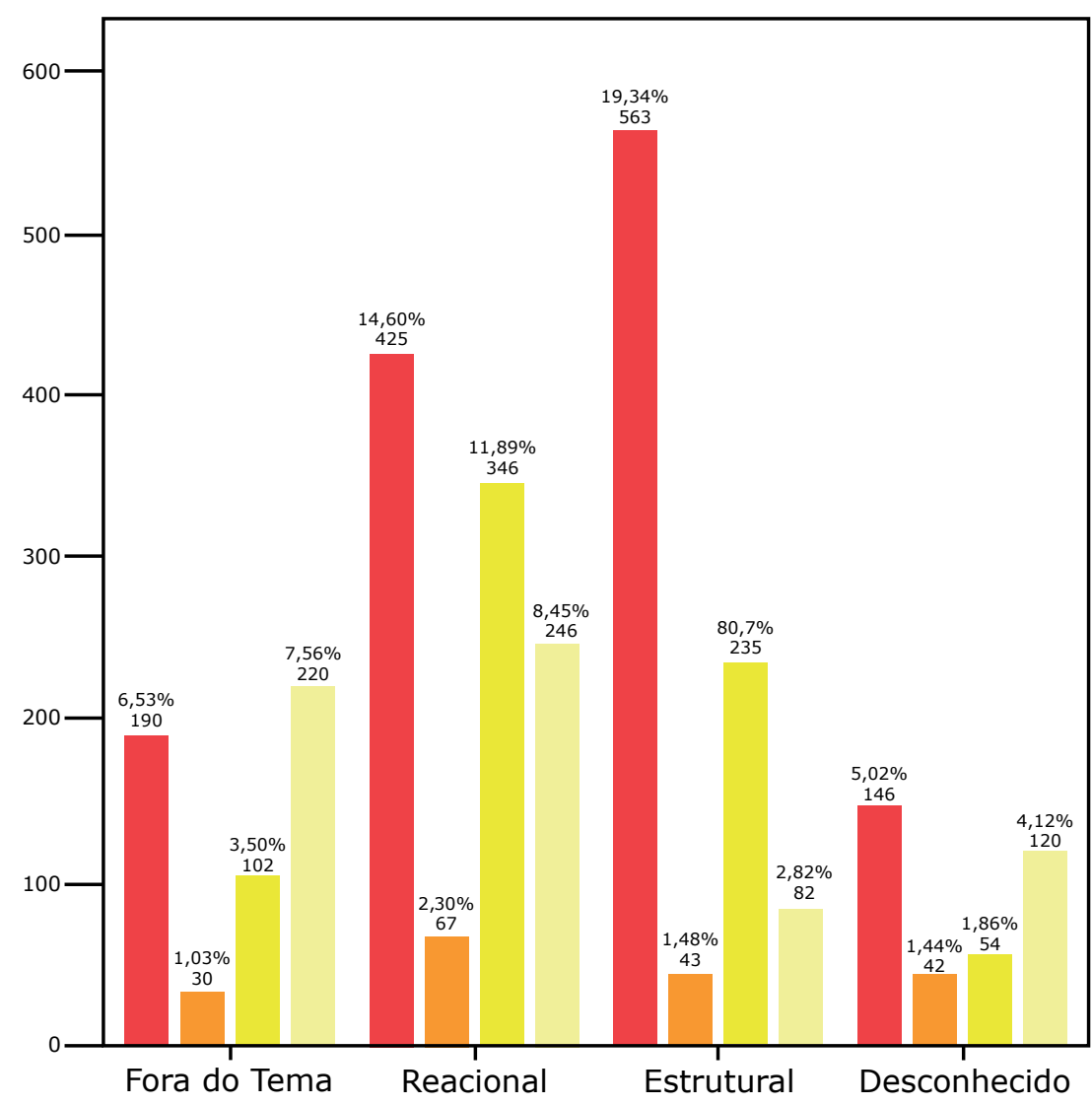

ESTRATÉGIA PERSUASIVA DOMINANTE

Retórica propositiva/ apelo pragmática

Retórica sedutora ou ameaçadora/ apelo emocional

Retórica ético-moral/ apelo ideológico

Retórica crítica/ apelo à credibilidade da fonte

Gráfico 2: Estratégia persuasiva dominante (tema)

Fonte: Elaborado pelos autores. 
A retórica ético-moral/apelo ideológico aparece mais nos comentários novos do que naqueles que são de resposta a outros comentadores, como é possível observar no Gráfico 3. A retórica propositiva predomina em ambos os turnos da fala, mas quando o comentário é uma resposta a outro usuário das redes, a retórica crítica aparece em segundo lugar, seguida da ético-moral e da sedutora, que também é a menos recorrente nos comentários novos.

A frequência da retórica crítica em respostas a outros comentários não é surpresa, já que esse tipo de intervenção, enquanto indicativo de engajamento, como é apontado por Stromer-Galley (2007), supõe uma conversação direta com um interlocutor e não o levantamento de um posicionamento pessoal desconectado que possa ser introduzido na abertura de uma nova caixa de comentário. O que fica evidente é que o turno da fala é uma variável do protocolo que não apenas indica a propensão ao diálogo ou possível recorrência excessiva aos mesmos argumentos já apontados, mas interfere na escolha das estratégias retóricas em questão.

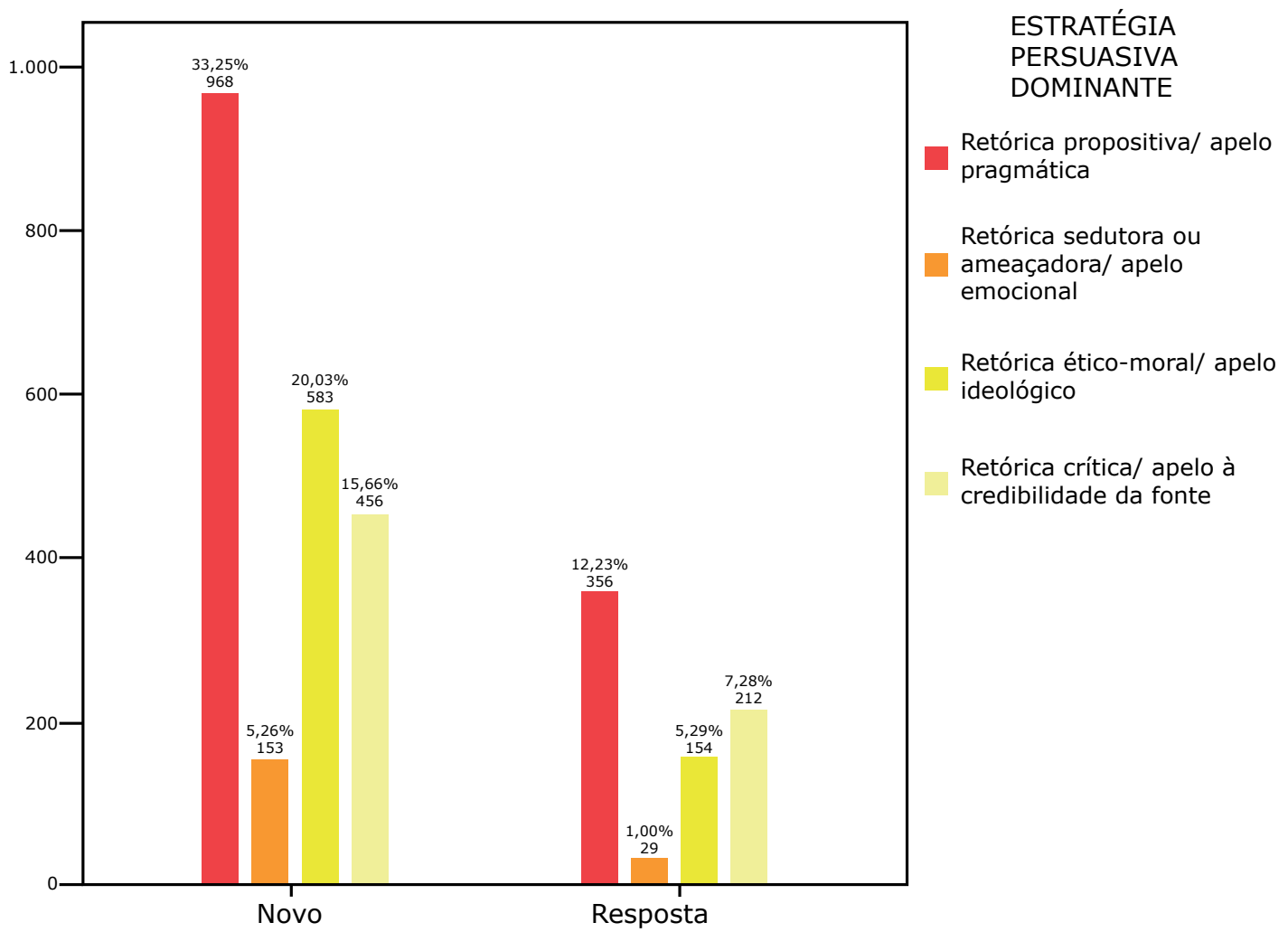

Gráfico 3: Estratégia persuasiva dominante (turno da fala)

Fonte: Elaborado pelos autores. 
Quando se observa a forma do comentário (V4), nota-se que os comentários declaratórios são predominantemente pragmáticos, mas há uma presença forte também dos pautados por questões ético-morais de apelo ideológico. Como era de se esperar, a retórica crítica é mais presente nos comentários que buscam estabelecer conflito. No entanto, é surpreendente que a retórica sedutora seja a menos frequente, até mesmo dentre os comentários declaratórios (Gráfico 4).

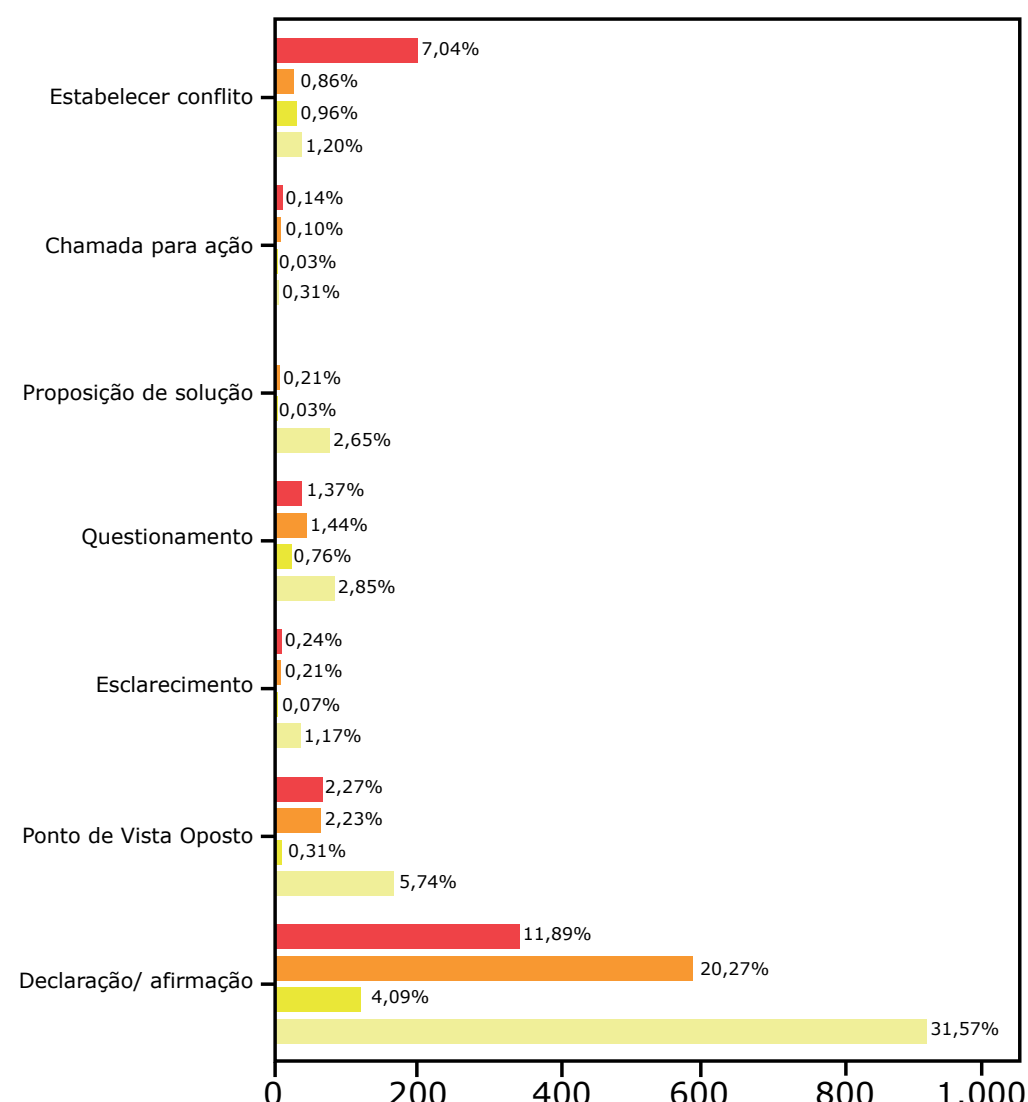

ESTRATÉGIA

PERSUASIVA

DOMINANTE

Retórica propositiva/ apelo pragmática

Retórica sedutora ou

ameaçadora/ apelo

emocional

Retórica ético-moral/ apelo ideológico

Retórica crítica/ apelo à credibilidade da fonte

Gráfico 4: Estratégia persuasiva dominante (forma)

Fonte: Elaborado pelos autores.

Outras variáveis importantes entre as que foram categorizadas na pesquisa dizem respeito aos recursos argumentativos utilizados pelos comentadores. Embora predomine nos comentários a ausência destes recursos, nos casos em 
que aparecem eles se comportam de maneiras diferentes em relação à estratégia persuasiva empregada (Gráfico 5).

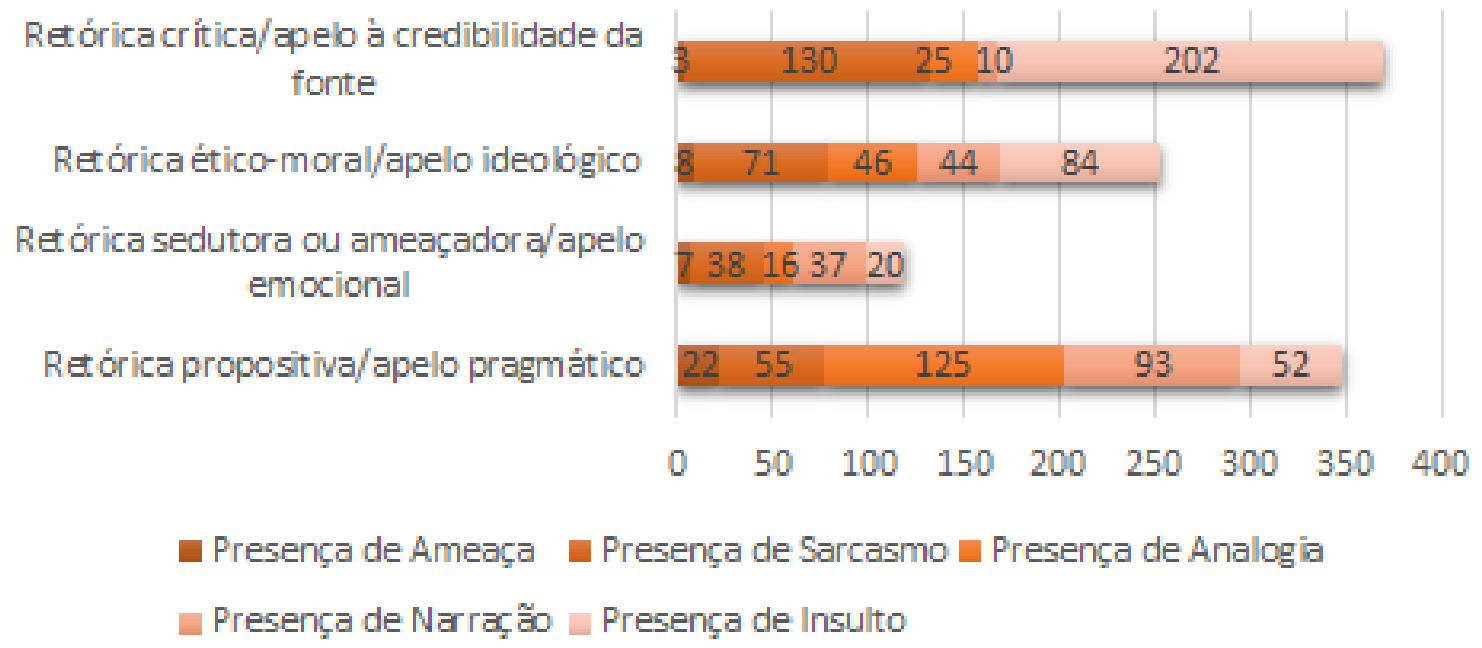

Gráfico 5: Presença de recursos argumentativos x Estratégia persuasiva dominante Fonte: Elaborado pelos autores.

O sarcasmo é bem mais evidente nos comentários críticos, muitas vezes destinado ao próprio interlocutor, como nos dois exemplos a seguir: "Quando a pessoa diz que estudou a revista Veja para se preparar... Santa ignorância Jesus!" e "e contra racismo e defende cota racial ta serto". São, em geral, comentários que atacam a pessoa, diretamente, ou questionam com ironia a lógica empregada por ela ao elaborar seu argumento, em alguns casos de maneira ofensiva.

Já a analogia é empregada mais por quem usa uma retórica propositiva ou com apelo pragmático, assim como a narração, embora essa última coincida mais com os casos em que a retórica é ameaçadora ou tem apelo emocional.

Destaca-se no entanto, o uso de insulto, presente em 12,3\% dos comentários analisados. São 533 comentários com teor ofensivo, dentre os quais 389 não permitem sequer identificar a quem a ofensa se destina. 84 são proferidos por pessoas contrárias às cotas e 60 por comentaristas favoráveis. Este dado indica que, como um tema polarizado, a discussão sobre as cotas raciais provoca reações 
acaloradas e menos cordiais. Aqui, este recurso coincide mais com a retórica crítica de apelo à credibilidade da fonte, mais uma vez em comentários rudes destinados ao interlocutor, conforme os exemplos a seguir:

\begin{abstract}
Você é um idiota. Pode negar o quanto quiser mas comece a enxergar a realidade e pare de acreditar em contos de fadas sobre "igualdade", "distribuição igualitária da riqueza" ou qualquer outro papo furado que os comunistas adoram contar para fazer a cabeça de pessoas inocentes como você. Estamos sob domínio da esquerda sim. E ela acabou com esse país nos últimos 30 anos e agora estão prestes a cair porque as pessoas finalmente estão saindo dessa bolha criada para iludir idiotas. Vou só Ihe citar a China, que também adota um sistema capitalista, somente para arrecadar dinheiro para se manter no poder. Mas eles são COMUNISTAS, não é só a direita que é capitalista. Sem dinheiro não há sistema que se sustente apenas com contos de fada para enganar trouxa. Você é uma tragédia social, fruto de uma sociedade segregadora. Alunos vagabundos tem até mesmo em escola de rico. Assista mais documentários e reportagens sobre a realidade das cidades deste país, para que deixe de digitar besteiras na net.
\end{abstract}

Contrariando as expectativas, os comentários que mais apresentam racionalidade, ou seja, que justificam seus posicionamentos, são os contrários às cotas e que empregam o argumento da igualdade, seguidos pelos contrários pautados no argumento de que as cotas deveriam ser sociais, não raciais. Entretanto, na soma total, os indivíduos favoráveis são levemente mais racionais que os contrários (79\% versus $77,4 \%$ dos comentários).

A Tabela 1 mostra o resultado do cruzamento da variável de racionalidade com o tipo de argumento utilizado:

\begin{tabular}{lcc}
\hline & $\begin{array}{c}\text { Número de } \\
\text { comentários com } \\
\text { racionalidade }\end{array}$ & $\begin{array}{c}\text { Porcentagem entre } \\
\text { os comentários com } \\
\text { racionalidade }\end{array}$ \\
\hline Contrário - Igualdade & 183 & $14,62 \%$ \\
\hline Contrário - Não há dívida histórica & 69 & $5,51 \%$ \\
\hline Contrário - "Racismo reverso" & 16 & $1,28 \%$ \\
\hline
\end{tabular}




\begin{tabular}{|c|c|c|}
\hline & $\begin{array}{l}\text { Número de } \\
\text { comentários com } \\
\text { racionalidade }\end{array}$ & $\begin{array}{l}\text { Porcentagem entre } \\
\text { os comentários com } \\
\text { racionalidade }\end{array}$ \\
\hline Contrário - Cota social & 147 & $11,74 \%$ \\
\hline Contrário - Meritocracia & 114 & $9,11 \%$ \\
\hline Contrário - Outro & 91 & $7,27 \%$ \\
\hline Contrário - Sem argumento, somente posicionamento & 70 & $5,59 \%$ \\
\hline Favorável - Dívida histórica & 91 & $7,27 \%$ \\
\hline Favorável - Questões social e racial são atreladas & 48 & $3,83 \%$ \\
\hline Favorável - Racismo estrutural da sociedade brasileira & 109 & $8,71 \%$ \\
\hline Favorável - Meritocracia é uma falácia & 93 & $7,43 \%$ \\
\hline Favorável - Outro & 83 & $6,63 \%$ \\
\hline Favorável - Sem argumento, somente posicionamento & 138 & $11,02 \%$ \\
\hline Total & 1252 & $100 \%$ \\
\hline
\end{tabular}

Tabela 1: V21 posicionamento do comentarista

Fonte: Elaborada pelos autores.

A racionalidade aparece irrisoriamente nos comentários que utilizam a ideia de "racismo reverso" como argumento, indicando possivelmente uma ausência de fundamentação para o argumento - ou seja, os comentaristas que empregam esta linha de raciocínio não buscam recursos e informações para respaldar sua opinião. Curiosamente, os indivíduos contrários às cotas raciais têm um número muito menor de comentários com posicionamento, mas sem argumento - quase metade do mesmo índice dos favoráveis, conforme apontado no segundo tópico do artigo.

Outro dado interessante em relação à racionalidade é que, nos comentários que apresentam justificação, as opiniões sobre o argumento da meritocracia 
são equilibradas entre as contrários e as favoráveis, aparecendo quase no mesmo nível em ambos os vieses.

Inferimos, portanto, que: (1) os sujeitos contrários à política das cotas raciais são os mais predispostos a elucidar um posicionamento seguido da apresentação de seus porquês; (2) apesar disso, não é possível evidenciar, a partir dos dados analisados, que essas justificações tenham caráter factível, já que há um desconhecimento a respeito das fundamentações e fontes a que os mesmos sujeitos recorrem, podendo se tratar de embasamentos voltados a si mesmos ou à disseminação do senso comum.

Por fim, ao contrapor o posicionamento dos sujeitos aos tipos de estratégia persuasiva das quais lançam mão (Gráfico 6), fica claro que a estratégia propositiva com apelo pragmático é a principal escolha dos comentadores, empregada em 392 casos pelos contrários e em 367 pelos favoráveis. Essa também é a retórica preferida nos comentários neutros ou naqueles em que não é possível determinar o posicionamento do comentador - 565 casos.

O comentário abaixo é um exemplo de conteúdo contrário às cotas e que faz uso de retórica propositiva com apelo pragmático.

\footnotetext{
Também não concordo com sistema de cotas. Acho que deveria existir nas faculdades públicas umas porcentagem grande das vagas para quem realmente sempre estudou na rede pública. Pois eu sempre estudei na rede municipal de ensino e posso afirmar, se não houvesse internet e cursinhos nunca teria visto geometria na minha vida. Pois, mesmo estando no currículo escolar, simplesmente não é apresentado nas maiorias das escolhas públicas. Logo podemos dizer que se um aluno se formar com 17 anos apenas na escola pública, ele desconhecerá ou terá menor envolvimento com varias matérias exigidas nos vestibulares. $\mathrm{E}$ mesmo aqueles que estudam em casa vão ter pouco envolvimento com certos assunto. Veja que se fazendo uma análise do que vimos na escolha e o visto em cursinhos ou estudando em casa, é fato que entendimento é muito mais limpo quando visto na escolha, o que permite uma evolução.
}

Trata-se de um texto mais longo do que a maioria, com argumentação desenvolvida e uma lógica que justifica seu posicionamento. Por outro lado, o exemplo seguinte ilustra uma lógica também contrária às cotas, mas com 
argumentação distinta: "bobagem, meu pai pobre ,minha muito pobre, sozinho em casa 3 dentistas e um medico, sem cota, sem socialismo besta, sem falso moralismo, meritocracia, bando de vagabundo cota é coisa de vagabundo".

Este exemplo representa a segunda estratégia mais empregada pelos contrários às cotas, a retórica ético-moral com apelo ideológico, que aparece em 337 casos, e em mais do que o dobro das vezes em que é empregada pelos sujeitos favoráveis às cotas (166). Estes, por sua vez, fazem uso da retórica crítica, com apelo à credibilidade da fonte, em 127 casos, mais do que os 86 aplicados pelos contrários. A retórica sedutora ou ameaçadora, com apelo emocional, é a menos aplicada, presente em 51 casos nos casos dos sujeitos contrários e 37 nos casos dos favoráveis.

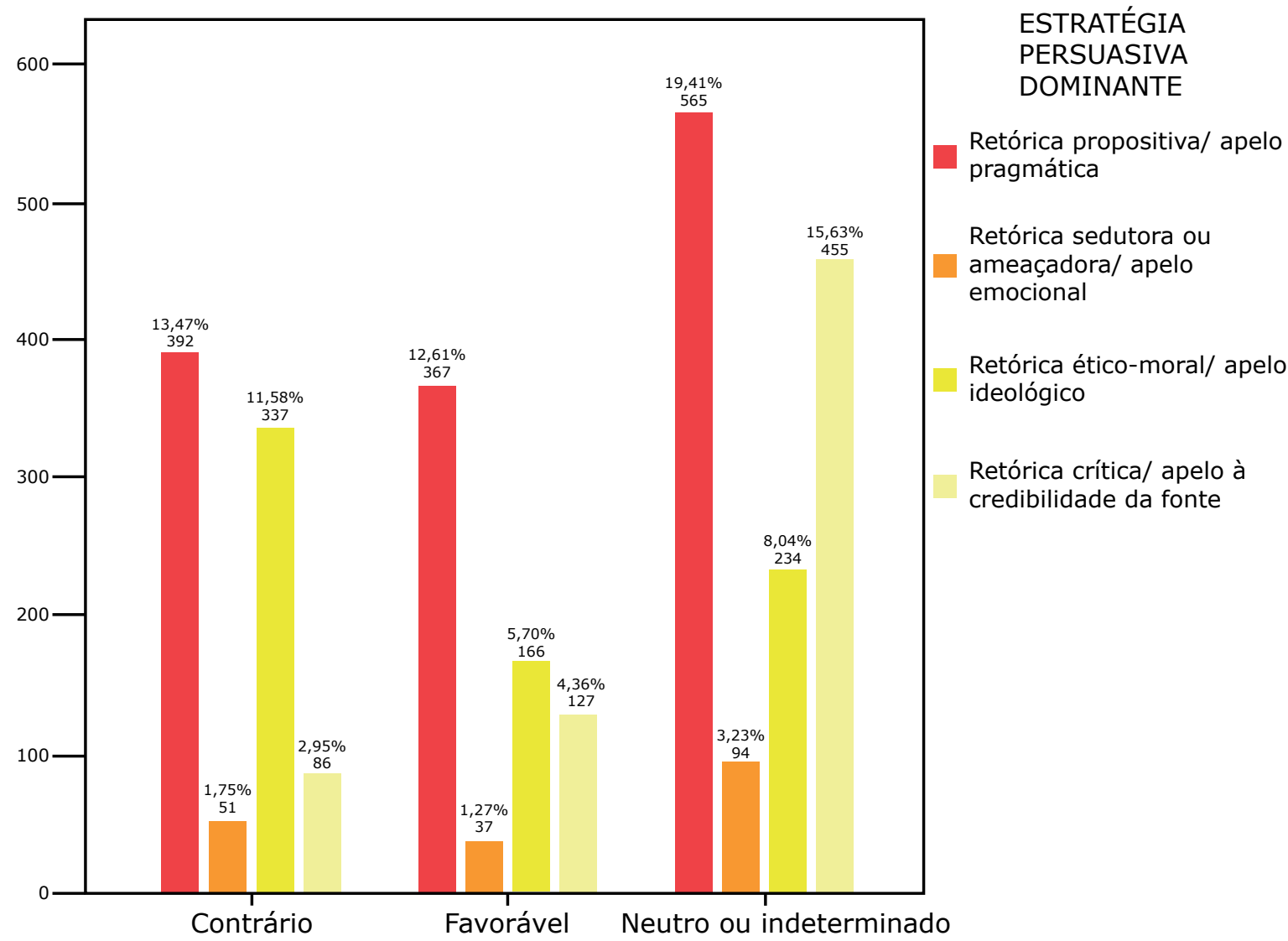

Gráfico 6: Posicionamento do comentário

Fonte: Elaborado pelos autores. 
Retomando o índice total de racionalidade $(41,4 \%)$ e a predominância de estratégias retóricas não emocionais, que são as propositivas $(30,5 \%)$, e as ético-morais (17\%), nota-se, a partir do corpus online, uma discussão pouco revestida de emoção. Esse fator, a princípio, está alinhado à perspectiva de Chambers (2009) de que retórica e razão, artifícios e argumentos, não são opostos, mas caminham juntos, já que o apelo à retórica também é necessário para que haja consideração de outros interlocutores em relação ao argumento exposto.

\section{Considerações finais}

Com base na perspectiva de autores da corrente deliberacionista que expandem e validam recursos de argumentação além da razão para a inclusão dos sujeitos no debate público, o artigo teve como objetivo verificar sob quais condições comunicativas as opiniões dos indivíduos contrários e favoráveis às cotas raciais nas universidades se formam e se expressam nas conversações online.

Os 4.333 comentários analisados a partir da coleta realizada no YouTube, no Facebook e no Twitter, em conjunto com a reflexão teórica acerca da política de cotas raciais no Brasil, apontam uma polarização do debate em torno desta temática, com equilíbrio entre posicionamentos contrários e favoráveis. A análise mostrou que estratégias retóricas não-emocionais são mais utilizadas em comparação às sedutoras, sendo que a principal escolha dos comentadores é a propositiva com apelo pragmático. Os resultados mostraram que os interlocutores contrários às cotas raciais estão mais predispostos a justificarem seus argumentos. A segunda estratégia mais empregada pelos contrários às cotas foi a retórica ético-moral, que é duas vezes mais empregada por eles do que pelos favoráveis. Em contraste, estes fazem mais uso da retórica crítica, com apelo à credibilidade da fonte.

Vale ressaltar, contudo, que o argumento mais utilizado pelos contrários às cotas é o princípio de igualdade, que desconsidera a presença do preconceito e da discriminação racial, tratando-se de um recurso de apelo ideológico em si. Caberá a pesquisas posteriores investigar, do ponto de vista da retórica, as conexões 
desse tipo de posicionamento com as perspectivas históricas construídas pelas elites nos processos de deliberação. Neste ponto, retomamos a perspectiva defendida por Bertúlio (2019) de que há um grande silêncio ao se tratar do racismo nas relações sociais brasileiras e, consequentemente, da difusão dessa "ideologia" nas esferas de poder político do Estado, revelando como a cultura jurídica e as práticas legislativas perpetuam os padrões de desigualdade racial e ajudam a disseminar essa visão para outras esferas da sociedade. Aqui percebe-se que, embora haja avanços nos estudos das relações étnico-raciais, boa parte da sociedade permanece alheia ao conjunto de problemas apresentados (BERTÚLIO, 2019).

Um dos desafios a partir deste estudo é avaliar em que medida a análise sobre os dados oferecidos pode ser aprimorada para o fortalecimento das teorias deliberativas, resgatando a leitura de que a retórica não é contraprodutiva para a deliberação democrática, mas permite construir estratégias mais eficientes de avaliação das formas de uso dessas estratégias como práticas validadas e recorrentes em discussões políticas (CHAMBERS, 2009).

\section{Referências}

BERTÚLIO, D. L. L. Direito e relações raciais: uma introdução crítica ao racismo. Rio de Janeiro: Lumen Juris, 2019.

BOTELHO, J. S.; MAIA, R. C. M.; MUNDIM, P. S. O debate em torno das cotas nas universidades públicas brasileiras de 2001 a 2009: uma análise preliminar. Compolítica, Brasília, DF, v. 1. n. 2, p. 10, 2011.

BRASIL. Projeto de Lei no 1332 , de 14 de junho de 1983. Dispõe sobre ação compensatória, visando a implementação do princípio da isonomia social do negro, em relação aos demais segmentos étnicos da população brasileira, conforme direito assegurado pelo artigo 153, parágrafo primeiro, da Constituição 
da República. Diário Oficial da União: seção 1, Brasília, DF, 1983. Disponível em: https://bit.ly/3mjCmiQ. Acesso em: 20 dez. 2021.

BRENNAN, R. L.; PREDIGER, D. J. Coefficient Kappa: some uses, misuses, and alternatives. Educational and Psychological Measurement, Santa Bárbara, v. 41, p. 687-699, 1981.

CHAMBERS, S. Rhetoric and the public sphere: has deliberative democracy abandoned mass democracy? Political Theory, Thousand Oaks, v. 37, n. 3, p. 323-350, 2009.

GARSTEN, B. The rhetoric revival in political theory. Annual Review of Political Science, Danvers, v. 14, n. 1, p. 159-180, 2011.

GOMES, J. B. B. Ação afirmativa e princípio constitucional da igualdade: o direito como instrumento de transformação social: a experiência dos EUA. Rio de Janeiro: Renovar, 2001.

HABERMAS, J. Direito e democracia: entre facticidade e validade. Rio de Janeiro: Tempo Brasileiro, 1997.

HABERMAS, J. The theory of communicative action: reason and rationalization of society. Boston: Beacon Press, 1984.

HASENBALG, C. Discriminação e desigualdades raciais no Brasil. 2. ed. Belo Horizonte: Editora UFMG, 2005.

MOEHLECKE, S. Ação afirmativa: história e debates no Brasil. Cadernos de pesquisa, São Paulo, n. 117, p. 197-217, 2002. 
MUNANGA, K. Políticas de ação afirmativa em benefício da população negra no Brasil: um ponto de vista em defesa de cotas. Sociedade e cultura, Goiânia, v. 4, n. 2, p. 31-43, 2001.

NASCIMENTO, A. "Racial democracy" in Brazil: myth or reality. Tradução de Elisa Larkin Nascimento. Ifé: University of Ife, 1976.

NASCIMENTO, A. A luta afro-brasileira no Senado. Brasília: Senado Federal, 1991.

NASCIMENTO, A. Sortilege: black mystery. Tradução de Peter Lownds. Chicago: Third World Press, 1978.

RIZZOTO, C. C. Livro de códigos: estratégias comunicacionais deliberativas em debates polêmicos e polarizados. Curitiba: Compa, 2019. DOI: http://dx.doi.org/10.5380/bdc/43.

RIZZOTTO, C. C. Racionalidade versus histórias de vida: uma análise das estratégias comunicacionais deliberativas em debates polêmicos e polarizados. Projeto de pesquisa. Processo no 427677/2018-1. Chamada MCTIC/CNPq n.o 28/2018. 2018.

RIZZOTTO, C. C.; BELIN, L. L. Debate além da fronteira: características deliberativas da conversação de brasileiros sobre a [não] descriminalização do aborto na Argentina. In: CONGRESSO DA COMPOLÍTICA, 8., 2019, Brasília, DF. Anais [...]. Brasília, DF: Compolítica, 2019. p. 1-25.

RIZZOTTO, C. C.; SARAIVA, A. Violência de gênero em debate: uma análise das conversações sobre a lei do feminicídio na fanpage do Senado Federal. Intexto, Porto Alegre, n. 49, p. 249-269, 2020. 
STROMER-GALLEY, J. Measuring deliberation's content: a coding scheme. Journal of Public Deliberation, Londres, v. 3, n. 1, 2007.

YOUNG, I. M. Inclusion and democracy. Nova York: Oxford University Press, 2002.

submetido em: 22 dez. 2020 | aprovado em: 6 abr. 2021 